\title{
Validation of a Graded Prognostic Model in Patients With Brain Metastases Treated With Whole-brain Radiotherapy Instead of Radiosurgery
}

\author{
CARSTEN NIEDER $^{1,2}$, BÅRD MANNSÅKER $^{1}$ and ROSALBA YOBUTA ${ }^{1}$ \\ ${ }^{1}$ Department of Oncology and Palliative Medicine, Nordland Hospital, Bod $\phi$, Norway; \\ ${ }^{2}$ Department of Clinical Medicine, Faculty of Health Sciences, University of Troms $\phi$, Troms $\phi$, Norway
}

\begin{abstract}
Background/Aim: The aim of this study was to analyze the survival predictions obtained from a recent graded prognostic model developed and validated in Japan. Patients and Methods: This was a retrospective singleinstitution analysis of 249 patients, managed with wholebrain radiotherapy for brain metastases. The sum of scores was calculated as in the Japanese study. The following parameters were included: number of brain metastases, volume of the largest lesion, sex, Karnofsky performance status, primary cancer type, control of primary cancer, and presence of extra-cerebral metastases. Results: Median overall survival was 3.0 months $(95 \%$ CI= 2.6-3.4 months). The median sum of scores was 12, range $=0-29$. Statistically significant differences were observed between all prognostic strata. Conclusion: The graded prognostic model is also applicable to patients treated with whole-brain rather than stereotactic radiotherapy.
\end{abstract}

Parallel to changes in the treatment of brain metastases from solid tumors, more advanced prognostic models have been developed (1-6). In recent years, different models for different types of primary tumors have been proposed, e.g., melanomaor renal cell carcinoma-specific prognostic scores (7-12). Nevertheless, a universally applicable score can still be considered advantageous due to its less complicated assignment in a busy working environment. Both three- and four-tiered scores have been validated and sometimes used

This article is freely accessible online.

Correspondence to: Carsten Nieder, Department of Oncology and Palliative Medicine, Nordland Hospital, 8092 Bod $\varnothing$, Norway. Tel: +47 75578449, Fax: +47 75534975, e-mail: carsten.nieder@nlsh.no

Key Words: Palliative radiation therapy, radiotherapy, brain metastases, prognostic model. for stratification in prospective clinical studies. Recently, Sato et al. have published a graded prognostic model for patients surviving 3 years or more after stereotactic radiosurgery (13). These authors assigned scores for seven statistically significant factors, i.e., number of brain metastases $1 \mathrm{vs.} 2-4$ $v s . \geq 5$ (score; 6/1/0), volume of the largest lesion $<10 \mathrm{ml} v s$. $\geq 10 \mathrm{ml}(4 / 0)$, female/male sex (5/0), Karnofsky performance status (KPS) $\geq 80 \%$ vs. $<80 \%$ (5/0), primary cancers of breast/lung/gastrointestinal tract/other $(1 / 0 / 3 / 0)$, controlled primary cancer $v s$. uncontrolled primary cancer $(8 / 0)$ and presence of extra-cerebral metastases $v s$. no extra-cerebral metastases $(5 / 0)$. Patients were categorized into four strata according to the sum of scores, i.e., 0-9, 10-19, 20-29 and 3036. The 3-year survival rates ranged between 0.7 and $45.1 \%$. The median survival was $3.6,6.8,15.0$ and 32.8 months, respectively. Relatively similar results were obtained in patients irradiated at a different institution in the same country (Japan), i.e. in a validation cohort (13). The aim of the present study was to provide additional data about the performance of this new prognostic model. In order to challenge its validity in several ways, patients managed in a different geographical region and with a different strategy (primary whole-brain radiotherapy, WBRT) were selected.

\section{Patients and Methods}

Analogous to previous validation studies (14-16), a single-institution database that includes all patients with unresected parenchymal brain metastases from histologically verified extracranial primary tumors managed with first-line WBRT was analyzed; both completed and interrupted treatment courses were included (according to the intention-to-treat principle; no previous prophylactic or other brain irradiation). The fractionation regimen was at the discretion of the treating physician. Further treatment for new or recurrent brain metastases was individualized. The strategies consisted of salvage surgery, stereotactic radiotherapy, systemic therapy or best supportive care (BSC). Systemic treatment was usually prescribed as judged appropriate by the patients' medical oncologists. The patients were treated between January 01, 2007 and 
December 31, 2019. Extracranial staging consisted of computed tomography (CT). If clinically relevant, other modalities were added to clarify $\mathrm{CT}$ findings, e.g., isotope bone scan, ultrasound, positron emission tomography etc. The sum of scores was calculated as described by Sato et al. (outlined in the previous paragraph) (13). Overall survival (time to death) from the first day of radiotherapy was calculated employing the Kaplan-Meier method, and different groups were compared using the log-rank test (SPSS 25, IBM Corp., Armonk, NY, USA). Only three patients were censored after median 4 months of follow-up. Date of death was known in all other patients. Univariate Cox regression was employed to analyze the validity of the prognostic score.

\section{Results}

The study included 249 patients, whose baseline data are shown in Table I. Median overall survival was 3.0 months [95\% confidence interval $(\mathrm{CI})=2.6-3.4$ months]. The median sum of scores was 12, range $=0-29$. The Cox regression analysis showed that the prognostic score (continuous variable) predicted overall survival $[p=0.0001$, Chi-square 26.4, $\operatorname{Exp(B)~0.948].~As~shown~in~Figure~1,~the~Kaplan-~}$ Meier survival curves were significantly different ( $p=0.0001$ pooled over all strata). None of the study patients had a favorable sum of scores, i.e., 30-36 points. Patients with 0 points $(n=8)$ had a median survival of 1.8 months (maximum 3.7 months). The respective figures were 2.1 months (5.0 months) for those with 1 point $(n=7)$.

\section{Discussion}

The validity of the new four-tiered score has already been demonstrated by Sato et al. (13). Their study included patients treated with stereotactic radiosurgery and was methodologically different from previous prognostic studies because the endpoint of interest was 3-year survival. The present results confirm the validity of the score in a very different population, both geographically and with regard to radiotherapy. Sato et al. reported a median survival time of 8.0 months and a median sum of scores of 15 (13). These figures illustrate that the WBRT study patients represent a negative selection (3.0 months, sum of scores 12 ). The study institution's policy was to offer surgery or stereotactic radiosurgery to patients with favorable prognostic features and brain metastases eligible for such treatment. Interestingly, the poor-prognosis group (0-9 points) had a median survival of 2.8 months, whereas Sato et al. reported 3.6 and 3.8 months, respectively (development and validation cohort). This relatively small difference increased with increasing sum of scores (20-29 points: 7.0 months after WBRT vs. 15.0 and 15.7 months in the Sato et al. study). In other words, stereotactic radiosurgery is increasingly beneficial in patients with better prognostic features, both regarding the higher likelihood of local
Table I. Patient characteristics.

\begin{tabular}{lrr}
\hline Baseline parameter & Number & Percent \\
\hline Female gender & 122 & 49 \\
Male gender & 127 & 51 \\
Non-small cell lung cancer & 104 & 42 \\
Breast cancer & 29 & 12 \\
Malignant melanoma & 24 & 10 \\
Small cell lung cancer & 25 & 10 \\
Renal cell cancer & 22 & 9 \\
Colorectal cancer & 18 & 7 \\
Other primary tumors & 27 & 11 \\
No extracranial metastases & 39 & 16 \\
Extracranial metastases & 210 & 84 \\
Controlled primary tumor & 158 & 63 \\
Uncontrolled primary tumor & 91 & 37 \\
Single brain metastasis & 31 & 13 \\
Two, three or four brain metastases & 101 & 41 \\
More than four brain metastases & 117 & 47 \\
Volume of the largest lesion <10 ml & 58 & 23 \\
Volume of the largest lesion $\geq 10$ ml & 191 & 77 \\
Performance status $\geq 80$ & 61 & 24 \\
Performance status <80 & 188 & 76 \\
Incomplete radiotherapy & 12 & 5 \\
Prescribed 10 fractions of 3 Gy without boost & 179 & 72 \\
Prescribed equivalent dose lower & 49 & 20 \\
than 10 fractions of 3 Gy & & \\
Prescribed equivalent dose higher & 21 & 8 \\
than 10 fractions of 3 Gy & & \\
Median age, range (years) & $65,28-90$ & \\
Median Karnofsky performance status, range & $70,30-100$ & \\
\hline
\end{tabular}

Equivalent dose was calculated with alpha/beta value $10 \mathrm{~Gy}$, higher doses than 10 fractions of $3 \mathrm{~Gy}$ were due to sequential or simultaneous integrated boost or administration of 15 fractions of $2.5 \mathrm{~Gy}$.

control and the lower likelihood of neurocognitive decline [endpoints that were not studied here, but in previous clinical trials reviewed in (17-19)].

In contrast to other prognostic models (20-22), the present one is not well suited to predict extremely short survival (even patients with 0 -1 points sometimes survived for more than 3 months). This fact is not surprising, given that 3-year survival was the landmark chosen by the Japanese group. Limitations of the present study include the relatively small number of patients and its retrospective design. Strengths of our study include the completeness of data (both baseline and follow-up) and the real-world setting (all age groups, different disease burden, inclusion of patients who failed to complete treatment). It is reassuring that a validation study in a vastly different setting was able to confirm the applicability of the score published by Sato et al.

\section{Conflicts of Interest}

The Authors declare that they have no conflicts of interest. 


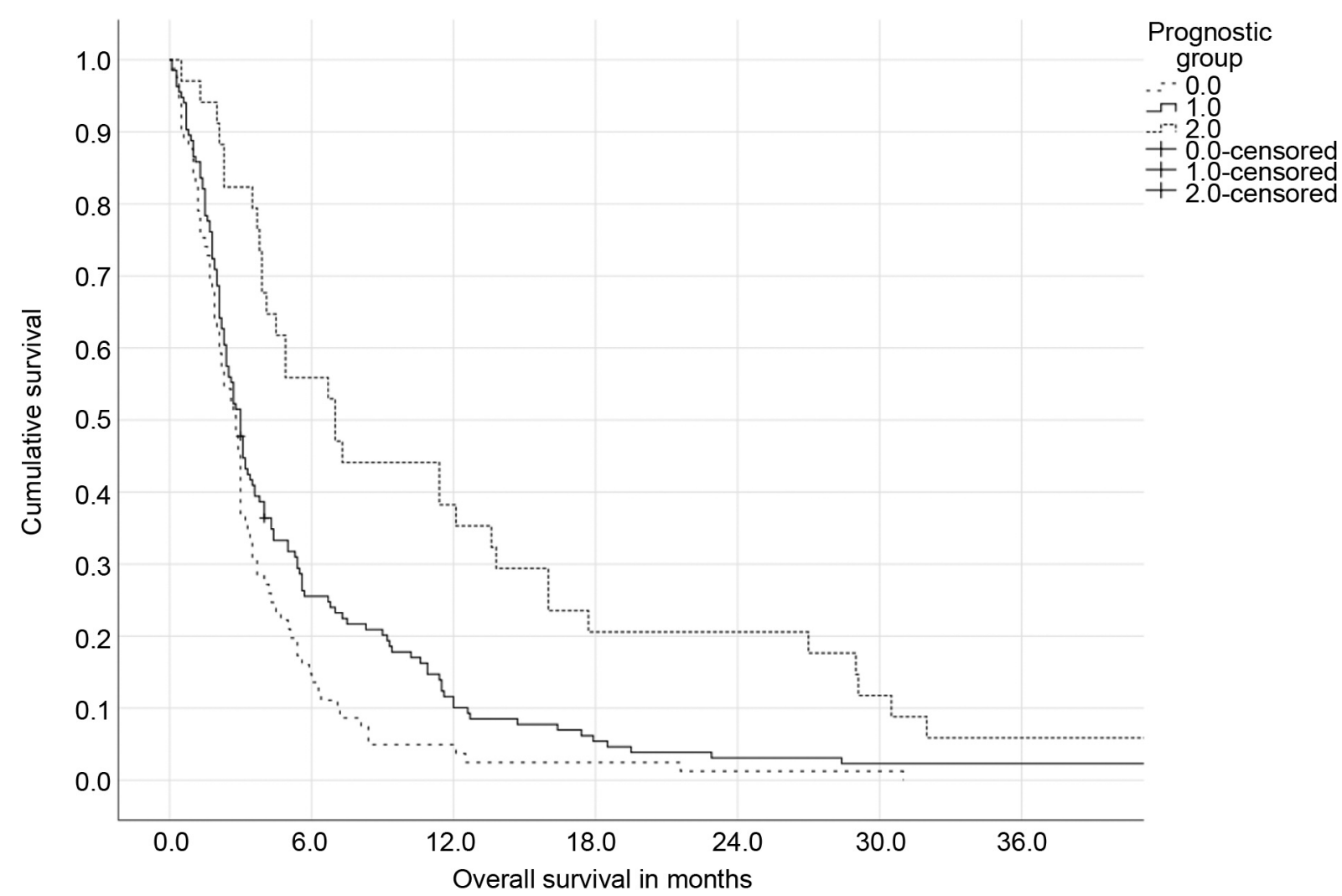

Figure 1. Actuarial overall survival stratified by the sum score ( $p=0.0001$ pooled over all strata). Eighty-one patients had 0-9 points (median survival 2.8 months, 3-year rate 0\%). The largest group $(n=134)$ had 10-19 points (median survival 3.0 months, 3-year rate $2 \%$ ). Thirty-four patients had 20-29 points (median survival 7.0 months, 3-year rate 6\%). Mean survival was 3.7, 7.3 and 14.3 months, respectively. The study did not include patients with 30-36 points. Pairwise comparison resulted in p-values of 0.025 (0 vs. 1), 0.00001 (0 vs. 2) and 0.001 (1 vs. 2), respectively.

\section{Authors' Contributions}

$\mathrm{CN}$ participated in the design of the study and performed the statistical analysis. CN, BM and RY conceived the study and drafted the article. All Authors read and approved the final article.

\section{References}

1 Rice SR, Bentzen SM, Hanna A, Choi E, Boggs DH, Kwok Y, Hyder J, Feigenberg SJ, Regine WF, Woodworth GF, Eisenberg HM, Yu C, Biggins TF, Barnholtz-Sloan JS, Sperduto PW, Weltman E and Mehta MP: Prognostic models for patients with brain metastases after stereotactic radiosurgery with or without whole brain radiotherapy: a validation study. J Neurooncol 140(2): 341-349, 2018. PMID: 30132164. DOI: 10.1007/s11060018-2958-6

2 Nieder C, Mehta MP, Geinitz H and Grosu AL: Prognostic and predictive factors in patients with brain metastases from solid tumors: A review of published nomograms. Crit Rev Oncol Hematol 126: 13-18, 2018. PMID: 29759555. DOI: 10.1016/j.critrevonc.2018.03.018

3 Lorenzoni J, Devriendt D, Massager N, David P, Ruíz S, Vanderlinden B, Van Houtte P, Brotchi $\mathrm{J}$ and Levivier M:
Radiosurgery for treatment of brain metastases: estimation of patient eligibility using three stratification systems. Int J Radiat Oncol Biol Phys 60(1): 218-224, 2004. PMID: 15337559. DOI: 10.1016/j.ijrobp.2004.02.017

4 Sperduto PW, Berkey B, Gaspar LE, Mehta M and Curran W: A new prognostic index and comparison to three other indices for patients with brain metastases: an analysis of 1,960 patients in the RTOG database. Int J Radiat Oncol Biol Phys 70(2): 510514, 2008. PMID: 17931798. DOI: 10.1016/j.ijrobp.2007.06.074

5 Rades D, Dunst J and Schild SE: A new scoring system to predicting the survival of patients treated with whole-brain radiotherapy for brain metastases. Strahlenther Onkol 184(5): 251-255, 2008. PMID: 18427755. DOI: 10.1007/s00066-0081831-5

6 Nieder C, Dalhaug A and Pawinski A: Serum lactate dehydrogenase contributes to prognostic assessment in patients with oligometastatic cancer and brain involvement. In Vivo 33(1): 229-232, 2019. PMID: 30587628. DOI: 10.21873/invivo.11464

7 Sperduto PW, Chao ST, Sneed PK, Luo X, Suh J, Roberge D, Bhatt A, Jensen AW, Brown PD, Shih H, Kirkpatrick J, Schwer A, Gaspar LE, Fiveash JB, Chiang V, Knisely J, Sperduto CM and Mehta M: Diagnosis-specific prognostic factors, indexes, and treatment outcomes for patients with newly diagnosed brain metastases: a multi-institutional analysis of 4,259 patients. Int $\mathbf{J}$ 
Radiat Oncol Biol Phys 77(3): 655-661, 2010. PMID: 19942357. DOI: $10.1016 /$ j.ijrobp.2009.08.025

8 Sperduto PW, Deegan BJ, Li J, Jethwa KR, Brown PD, Lockney N, Beal K, Rana NG, Attia A, Tseng CL, Sahgal A, Shanley R, Sperduto WA, Lou E, Zahra A, Buatti JM, Yu JB, Chiang V, Molitoris JK, Masucci L, Roberge D, Shi DD, Shih HA, Olson A, Kirkpatrick JP, Braunstein S, Sneed P and Mehta MP: Estimating survival for renal cell carcinoma patients with brain metastases: an update of the renal graded prognostic assessment tool. Neuro Oncol 20(12): 1652-1660, 2018. PMID: 30418657. DOI: 10.1093/neuonc/noy099

9 Sperduto PW, Yang TJ, Beal K, Pan H, Brown PD, Bangdiwala A, Shanley R, Yeh N, Gaspar LE, Braunstein S, Sneed P, Boyle J, Kirkpatrick JP, Mak KS, Shih HA, Engelman A, Roberge D, Arvold ND, Alexander B, Awad MM, Contessa J, Chiang V, Hardie J, Ma D, Lou E, Sperduto W and Mehta MP: Estimating survival in patients with lung cancer and brain metastases: An update of the graded prognostic assessment for lung cancer using molecular markers (Lung-molGPA). JAMA Oncol 3(6): 827 831, 2017. PMID: 27892978. DOI: 10.1001/jamaoncol. 2016.3834

10 Nguyen T, Janssen S, Schild SE and Rades D: A simple implement for assessing the survival of elderly patients with melanoma irradiated for cerebral metastases. In Vivo 34(3): 1361-1364, 2020. PMID: 32354931. DOI: 10.21873/invivo.11914

11 Nieder C, Marienhagen K, Geinitz H and Grosu AL: Can current prognostic scores reliably guide treatment decisions in patients with brain metastases from malignant melanoma? J Cancer Res Ther 7(1): 47-51, 2011. PMID: 21546742. DOI: 10.4103/09731482.80458

12 Sperduto PW, Jiang W, Brown PD, Braunstein S, Sneed P, Wattson DA, Shih HA, Bangdiwala A, Shanley R, Lockney NA, Beal K, Lou E, Amatruda T, Sperduto WA, Kirkpatrick JP, Yeh N, Gaspar LE, Molitoris JK, Masucci L, Roberge D, Yu J, Chiang V and Mehta M: Estimating survival in melanoma patients with brain metastases: An update of the graded prognostic assessment for melanoma using molecular markers (Melanoma-molGPA). Int J Radiat Oncol Biol Phys 99(4): 812-816, 2017. PMID: 29063850. DOI: 10.1016/j.jijrobp.2017.06.2454

13 Sato Y, Yamamoto M, Serizawa T, Yamada KI, Higuchi Y and Kasuya H: A graded prognostic model for patients surviving 3 years or more (GPM $\geq 3$ Ys) after stereotactic radiosurgery for brain metastasis. Radiother Oncol 156: 29-35, 2020. PMID: 33249092. DOI: 10.1016/j.radonc.2020.11.024
14 Nieder C, Dalhaug A and Pawinski A: External validation of the LabBM score in patients with brain metastases. J Clin Med Res 11(5): 321-325, 2019. PMID: 31019625. DOI: 10.14740/jocmr3746

15 Nieder C, Hintz M, Oehlke O, Bilger A and Grosu AL: Validation of the graded prognostic assessment for lung cancer with brain metastases using molecular markers (lung-molGPA). Radiat Oncol 12(1): 107, 2017. PMID: 28651600. DOI: 10.1186/s13014-017-0844-6

16 Nieder C, Hintz M, Bilger A, Oehlke O and Grosu AL: Validation of the graded prognostic assessment for melanoma using molecular markers (Melanoma-molGPA). J Clin Med Res 10(3): 178-181, 2018. PMID: 29416574. DOI: 10.14740/jocmr3248w

17 Suh JH, Kotecha R, Chao ST, Ahluwalia MS, Sahgal A and Chang EL: Current approaches to the management of brain metastases. Nat Rev Clin Oncol 17(5): 279-299, 2020. PMID: 32080373. DOI: 10.1038/s41571-019-0320-3

18 Moravan MJ, Fecci PE, Anders CK, Clarke JM, Salama AKS, Adamson JD, Floyd SR, Torok JA, Salama JK, Sampson JH, Sperduto PW and Kirkpatrick JP: Current multidisciplinary management of brain metastases. Cancer 126(7): 1390-1406, 2020. PMID: 31971613. DOI: 10.1002/cncr.32714

19 Kraft J, Zindler J, Minniti G, Guckenberger M and Andratschke $\mathrm{N}$ : Stereotactic radiosurgery for multiple brain metastases. Curr Treat Options Neurol 21(2): 6, 2019. PMID: 30758726. DOI: 10.1007/s11940-019-0548-3

20 Nieder C, Marienhagen K, Dalhaug A, Aandahl G, Haukland E and Pawinski A: Prognostic models predicting survival of patients with brain metastases: integration of lactate dehydrogenase, albumin and extracranial organ involvement. Clin Oncol (R Coll Radiol) 26(8): 447-452, 2014. PMID: 24702741. DOI: $10.1016 /$ j.clon.2014.03.006

21 Lewitzki V, Klement RJ, Hess S, Kosmala R, Nieder C and Flentje M: External validation of a prognostic score predicting overall survival for patients with brain metastases based on extracranial factors. Clin Transl Radiat Oncol 16: 15-20, 2019. PMID: 30906886. DOI: 10.1016/j.ctro.2019.02.005

22 Nieder C, Hess S and Lewitzki V: External validation of a prognostic score for patients with brain metastases: Extended diagnosis-specific graded prognostic assessment. Oncol Res Treat 43(5): 221-227, 2020. PMID: 32213772. DOI: 10.1159/000506954

Received January 15, 2021

Revised February 4, 2021 Accepted February 10, 2021 